\title{
STEPPING OUT OF THE CLASSROOM INTO VIRTUALITY: USING MMORPGs TO TEACH HISTORY
}

\author{
Solomon K. Smith \\ Georgia Southern University
}

A major problem for teaching history is the difficulty of getting students interested in the materials and making sense of the coherent narrative of historical events presented in class. Through lectures, discussions, assignments, films, and reading materials, instructors try to demonstrate a thematic order to their subjects, but many find that students struggle to make sense of the material or to restructure it into a clear historical narrative at the end of the semester. Even when they do make sense of the narrative, students often fail to see the value of the subjects they studied. In many ways, the problem for historians is effectively enabling students to understand the relationship between the day-to-day existence of people and the sweeping historical events occurring in the past as well as those during the students' own lifetimes. This problem leads to an important question for the teaching profession: Can nontraditional methods like using video games in the classroom aid in teaching history and possibly even create an active learning environment?

A growing body of experience and literature suggests that video games can be used as effective teaching tools for history, depending on how they are employed. ${ }^{1}$ Beyond offering students a new way to learn about the past, video games give them an opportunity to come into direct contact with history by allowing them to actively participate in a re-creation of historical events. For the past six years, I have allowed my students in upper division history courses (usually twenty to twenty-five students) the opportunity to play video games as part of the selection of class assignments offered to them. The others are more traditional assignments used in history courses: film reviews, argumentative essays based on reading materials, and a short research paper

\footnotetext{
'Scott Carlson, "Can Grand Theft Auto Inspire Professors?" Chronicle of Higher Education, August 15, 2003; James Gee, What Video Games Have to Teach Us About Learning and Literacy (New York: Palgrave Macmillan, 2004); James Gee, "Learning by Design: Good Video Games as Learning Machines," E-Learning 2 (2005): 5-16; Jeremiah McCall, "Using Simulation Games in the History Classroom," http://teachinghistory.org/nhec-blog/25117. This piece is the first in a six-part blog series. See also the Roundtable: Games and History: A New Way to Learn or Educational Fluff?, http://teachinghistory.org/ issues-and-research/roundtable/25080; Marc Prensky, Digital Game-Based Learning (New York: McGraw-Hill, 2004); Kurt Squire and Sasha Barab, "Replaying History: Engaging Urban Underserved Students in Learning World History Through Computer Simulation Games" (paper presented at the International Conference of the Learning Sciences, Santa Monica, CA, 2004); Nicolas Trépanier, "The Assassin's Perspective: Teaching History with Video Games," Perspectives in History 52 (May 2014), http://www.historians.org/publications-and-directories/perspectives-on-history/may2014/the-assassin $\% \mathrm{E} \% 80 \% 99$ s-perspective\#; Robert Whitaker, "Backward Compatible: Gamers as a Public History Audience," Perspectives on History 54 (January 2016), https://www.histsorians.org/ publications-and-directories/perspectives-on-history/january-2016/backward-compatible-gamers-as-apublic-history-audience\#.
} 
of seven to ten pages. Interestingly, when given a choice, most students decided to take the nontraditional gaming option rather than conduct the short research paper. Because immersion in primary sources is integral to understanding history, all students in the class are required to submit primary source document analysis papers. They also take two exams covering course materials. Thus, students are given an array of assignments in order to engage with the materials in the course.

Although I believed that the video game assignments were a valuable way to engage with the class materials, I always made them optional so that students who were not comfortable with or not interested in video games could choose an alternate activity. But since the video gaming exercises were becoming increasingly popular and worked so well as historical instruction, I decided to do something different for a new class titled "Privacy in the Americas," created for the spring 2012 semester. $^{2}$ Every student was required to play a video game as part of a major course assignment (the entire assignment, which included several components, was worth forty percent of their grade). Hence, gaming was no longer optional. Although there are several stand-alone games that could have been useful for this exercise, I opted not to use them because it would require students to purchase the software. Instead, I had the students play a free massive multiplayer online role-playing game (MMORPG) for this course. ${ }^{3}$ Cost was a big reason for the selection of a MMORPG, but it was also due to the historical focus of the games being used and the possibility of the students being able to interact with each other during game play.

MMORPGs are useful teaching devices because they are a blend of genres, mixing role-playing action and strategy elements in the form of web browser-based games that can be accessed by either computer platform (iOS or PC; some are even available on gaming consoles like PlayStation and Xbox). MMORPGs are appealing because they allow students to interact and learn from each other in the game as well as with the general gaming community that plays the game for entertainment. Just as important, students as a whole are already experienced with MMORPGs, so it is not necessary to teach them how to play. As in all role playing games (RPG), the student players create a character and take control over that character's actions. In many cases, the environment within the game is extraordinary in its historical accuracy, even if situations created by gameplay are not historical. For example, one game began with a tutorial that taught gameplay to players by requiring them to escape from a sinking historically accurate Spanish galleon from the eighteenth century while it was under

${ }^{2}$ In fact, this class has been so popular that I have taught it three times since its creation.

${ }^{3}$ Historical settings have been covered by an endless stream of video games. For my class, "Piracy in the Americas," there are several standouts. Cutthroats: Terror on the High Seas and Sid Meier's Pirates! are easily the best of the genre and the most useful in teaching about piracy and the Caribbean during the Golden Age of Sail. 
attack by zombies. It is also important to note that the world of MMORPGs continues to exist and change while the player is offline and away from the game, forcing students to consider what will happen to their characters (and their character's property) when they are not playing.

Although there are a number of MMORPGs covering a wide variety of historical subjects and periods, I decided to use two specific games for my upper division class "Piracy in the Americas" because both had maritime themes, they were both reasonably accurate in their historicity, and they fell within the time period addressed during the class, roughly 1550 to 1820 . Another important caveat was that both games were free to play, so students would not have to buy expensive software. The first game was Flying Lab Software's Pirates of the Burning Seas, which I used in class for two different semesters. When the company offering Pirates of the Burning Seas suffered a data breach and shut the game down for several months, I switched to a new game called Unchartered Waters Online by KOEI. ${ }^{4}$ Both of these games worked well for my assignments, but they stressed the development of different skills and knowledge by the students which are worth exploring.

Pirates of the Burning Seas is set in the Caribbean in an anachronistic 1720, mixing ahistorical characters and events with a relatively accurate geography as well as adding economic, political, and diplomatic situations that match what was happening within the region during the period. Although the game offers the opportunity to follow a story line, gameplay is open. Student success depends on their ability to combine tactical ship battles and swashbuckling combat in port battles with participation in a player-driven economy. Players choose nationality affiliation from four nations: Great Britain, Spain, France, or Pirates. Each nation has specific ships, economic opportunities, and colonies/trade ports within the Caribbean. Players are also required to select a career path. For nationals (British, Spanish, French), the careers are: Naval Officer, Privateer, or Freetrader; Pirates are limited to being either a Cutthroat or a Buccaneer. Career paths determine what abilities and features players will accrue as a captain, and along with nationality, drive specific choices in gameplay. During times of war, players can find themselves economically constrained or even attacked while in port or on the high seas due to their national affiliation. Pirates can freely operate as they please, but will find little support from nations whose subjects they attack.

There are two major components of gameplay in Pirates of the Burning Seas: combat and participation in the player-driven economy. Both activities have an educational value. Players engage in combat in three arenas-swashbuckling, port contention, and ships. Swashbuckling expands the character's skills and helps them

\footnotetext{
${ }^{4}$ Flying Lab Software's Pirates of the Burning Seas was originally offered by Sony Online Entertainment, but was dropped in December 2012 after the data breach. As a result, former members of Flying Lab Software formed Portalus Games to run the game and host it, which they have done since 2013.
} 
gain rank, both useful for gameplay. Port contention is the capture of player-owned ports throughout the Caribbean, many of which feature historically accurate defenses. If the players succeed, they take control of the port and all commodities in it. They also must begin running the port's economic activities and rebuild defenses. Obviously, control of a port opens the player to attack, so it is important to be prepared as quickly as possible, which requires players to work together to gather materials. The final type of combat is ship-to-ship and can involve any of the fifty-five historically accurate ships of the period. Combat in Pirates of the Burning Seas can advance character development but also teaches the students knowledge about the historically correct military characteristics of weapons, ships, fortifications, and ports.

One of the most interesting aspects of the combat portion of the game is that it led students to begin doing their own research on ships as well as the naval strategies and tactics during the period. The assigned reading for the course is mostly primary materials like several of William Dampier's various works, Alexandre Exquemelin's History of the Buccaneers of America, Charles Johnson's A General History of the Robberies and Murders of the Most Notorious Pyrates, and a collection of court documents; I only use one secondary source, David Cordingly's Under the Black Flag. While these materials offer some details about combat, the students were not satisfied. Many started seeking out naval texts from the period to expand their knowledge and combat abilities. Other students realized from my description of Castillo de los Tres Reyes Magos del Morro in Havana during a lecture that the game had an exact duplicate of the fortress, which led them to assume all the fortifications in the game were close to or identical to the real sites. Hence, they sought out engineer plans as well as historical accounts of how the various fortifications were defeated in real life and employed those tactics in the game.

The second type of activity students engage in while playing Pirates of the Burning Seas is the player-driven production based economy. Players can locate raw materials to sell to manufactories or establish their own production line to build finished goods. One of the best examples for a production line involves timber. Wood of various types can be harvested from several historically accurate locations across the Caribbean in order to be manufactured into finished goods by player owned lumber mills or shipyards. The finished goods can either be sold to other players or used by the producer. Within this process, students will have to understand the steps required for production and acquire the necessary goods needed along the pathway. For example, a ship is composed of a hull that is made of planks cut from trees. Along with wood, a ship needs nails, masts, cannons, several hundred yards of rope, sails, and so on-each item has its own production line and offers players an opportunity to establish their own manufacturing centers or purchase materials from other players.

The various production lines in the game are intricate in their detail, but students with historical knowledge as well as a grasp of Caribbean geography have a distinct advantage since many resources can be found in their historical locations. As a result, students quickly learned to research the geography and economy of the historical period 
in order to advance themselves in the game. One student realized from reading a primary source by William Dampier that pirates and others hard on their luck would cut exotic woods in a location called Darien during the Age of Caribbean Piracy. Searching on the game map, the student located Darien in modern Panama and went to make his fortune, finding valuable exotic woods and a crew interested in joining his pirate ship. When other students read about his exploits on a class-shared blog, they, too, sought out historical locations for commodities valuable in the game, leading some to mine salt-peter and harvest natural salt pans while another discovered a silver mine previously unknown to players in the game.

While Pirates of the Burning Seas is based in one geographic region of the world and is largely driven by the player-based economy, Unchartered Waters Online focuses on exploration and offers students the opportunity to travel the world. Set in the Age of Exploration, the player takes up the role of a ship captain in a largely open-ended world. Like Pirates of the Burning Seas, players choose from six nationalities (England, Dutch Republic, Ancien Régime in France, Spanish Empire, Kingdom of Portugal, and Republic of Venice) and select a basic class: adventurer, merchant, or soldier. Unlike Pirates of the Burning Seas, the plot is loose and does not have a linear storyline. Instead, the game requires a player to follow a specific narrative path based on their nationality and career path as a tutorial to learn how to play the game. By the end of the tutorial storyline, players will have increased their exploration skills, explored large sections of the world, managed a seagoing fleet, and participated in expeditions geared toward a chosen trade: privateering, treasure hunting, exploration, and even piracy.

Exploration during the age of sail is the biggest educational benefit of Unchartered Waters, but student participation in trade between the major ports of the world also helps them learn geographic locations as well as the specialized economic products of various regions. As they move from port to port, players are encouraged to buy commercial products and move them around the local economies. The goods available in each port are historically and regionally accurate, so a little research by students can open up opportunities to make money in the game as well as learn about regional economic activities. Participation also expands a player's wealth, opens up new ships for purchase, and expands access to better equipment like sails, ropes, hulls, and weapons.

While students did not have the same "aha" moments in Unchartered Waters, several of them did find historical similarities they were able to exploit in the game. For one, several students realized that the water currents and winds seemed to follow a particular pattern. After consulting navigational charts for the Atlantic Ocean, they realized it was a near exact copy of the wind patterns and currents from real life. Hence, they were able to travel within the game safer and quicker. Another group of students realized that the commodities available for trade in the various ports matched what could be found during the historical time in question, and thus they were able to capitalize on moving valuable items from places where they were plentiful and cheap 
to areas where they were rare and valuable. Although students first tried to find good places to trade by trial and error, one shared on a blog that she found trade information in an assigned primary source and the rest of the students began to scour them for clues. In both games, students were using historical knowledge to achieve game success, a skill I believe will help them also in real life.

Regardless of which game the students played, the major assignment associated remained the same. While playing the game, the students were required to keep a captain's log of their adventures. For these logs, students were encouraged to keep highly detailed records, including audio or video recordings, and screen captures from the game. Since the primary sources used to teach the class included diaries, memoirs, personal accounts, judicial proceedings, and government documents from the period between 1550 and 1730, I encouraged the students to mimic those items while creating their own documentation. As a result, students got a sense of how primary documents are created while detailing their own adventures. Furthermore, I required students to put their captain's log in blog format so that they would gain experience with the online publication process. Our university has found that employers increasingly seek employees with these skills, so this assignment can give them a little experience if they do not already have it. Students share their blogs with the class, so, as already detailed by several examples, they can learn from each other's experiences as well as find details for locating each other in the game. Although the students learned a lot from the blogging process, ultimately the purpose of the logbook is to have students create their own primary source materials, which they will use for the final part of this assignment: a written history of their character's activities over the course of the semester, with their logbook being the primary source along with others created by peers in the class for their character "histories." Along with their created "primary sources," students are encouraged to compare their exploits in the game to those of real pirates and mariners they read about within the assigned primary source materials for the class.

The MMORPG assignment combines both active and interactive learning processes. As a result, it allows for greater degrees of comprehension of course materials as well as mental retention of lectures and primary sources. Because the students actively engage in the creation of historical events within the game and through interaction with their peers and other players, they develop an understanding of how historical sources are created and the difficulty of writing a cogent history based on those materials. Thus, the historical process becomes transparent for the students, since they go through every step of the historical process just as historians do. In a way, the students go beyond the historical process since they are learning how primary documents are created as they decide what they will or will not record in their gameplay logbooks.

This assignment also has another intrinsic value that makes it an appealing teaching device. Since the students engage in each level of the historical processparticipation in the event by playing the game, creation of historical documents by maintaining the logbook, and the writing of history of their character in the game - they 
learn the intricacies of researching and writing in a way they would not normally do if they just wrote the regular research paper commonly assigned in history courses. In my teaching experience, students tend to rely almost exclusively on internet resources when writing papers, regardless of any strict parameters set for the assignment. As a result, I am finding a greater number of incidences of fraud and plagiarism when I assigned traditional research papers in the past; increasingly, students struggle to discern between proper research and misappropriation of another authors' work. So far, the video game assignment has remedied the plagiarism problem. Since the student history of the character depends on the logbook entries about events specifically in the gameplay, rather than finding information about a historical event in the public sphere, the opportunity for the student to purchase work does not exist.

While the MMORPG assignment has been a useful teaching tool, a few major concerns need to be acknowledged: historical accuracy, possible malicious or insincere motivations of individuals within the larger gaming community, and gaming community demographics that can impact player interactions. Video games are designed to entertain, not to teach history. While most designers research a game's historical period, they are not scholars who have historical accuracy as a primary concern. That noted, this is not necessarily a limitation. Sometimes the inaccuracies offer a pretext for historical discussion within class and can lead to many important questions: What factors led the game designers to include the inaccuracies in the first place? Did cultural influences, such as concerns of offending players, shape the way in which they present history? How did the various inaccuracies relate to ethical and commercial considerations? In my experience, students are fascinated by the notion that there could be a reason for the game designers to include a historical inaccuracy. For example, despite the religious issues that existed between the various European countries during the period, which often drove their historical interactions, neither MMORPG I used in class had a religious component as part of gameplay. When I pointed out the nonappearance of religion to the students, a long discussion ensued about the role of religion in history and the creation of historical events as well as the arguments that exist between historians in regard to these issues. As a result, the classroom discussion of historical inaccuracies in the game led to a debate over the relationship between general historical inaccuracies and ongoing historical arguments.

The discussion of historical accuracy also led the students to grow keenly aware of the need to evaluate the reliability of historically themed modes of entertainment. As a result, the topic of historical inaccuracies brought the students closer to the work of actual scholarly research. It also led the students to recognize that historical inaccuracies can be broken down into the same subcategories defined by Nicolas Trépanier in his discussion of the somewhat historically based video game Assassins Creed. These categories include, but are not limited to: aesthetics (the visual appearance of ships and port layouts), passive narrative elements (scenes that provide background and pretext to player actions), and psychology (asking, for example, if the punishment/reward system built into the game mechanics corresponds to the cultural 
context of the Age of Sail). By recognizing these subcategories, the students came to understand the unique characteristics of video games and MMORPGs as a medium to convey historical information beyond just a three-dimensional environment to enjoy a fun experience. ${ }^{5}$

The second concern to be considered when using MMORPGs as a tool to teach history involves the online gaming community. Different types of people play internet games, and a single group known as trolls - those inclined towards malicious intentcan be problematic for instructors using MMORPGs. ${ }^{6}$ Trolls are found all over the internet and are difficult to avoid. Although students are generally familiar with these provocateurs, teachers should remind them that such individuals exist in the gaming world. It may even be necessary to help students report negative behavior if they witness or are the object of trolling activity.

Another issue with the gaming community involves demographics and player interactions. Most people playing MMORPGs are male, between the age of 19 and 32; only $15 \%$ of gamers in MMORPGs are female. ${ }^{7}$ Hence, female students will receive more attention than their male counterparts in the game if they create female characters. Female characters often are more likely to receive gifts and help from other players. While this attention may be useful for gameplay, it can pose a distraction and become problematic when gift giving players expect something in return. As a result, students should be warned to be careful with their interactions and treat them just as they do in real life. In spite of these issues, the majority of the gaming community is filled with good people seeking enjoyment and entertainment.

While other assignments and activities in a history course will teach the students facts and figures of various events, movement, and historic connections, whether just in the past or stretching into the present, utilization of MMORPGs and other video games can be an excellent way to engage students beyond textbooks and lectures. In many ways, my course's MMORPG assignment even helped the students to understand what historian Andrew McMichael identifies as "how western culture packages, 'uses,'

${ }^{5}$ Nicolas Trépanier, "The Assassin's Perspective: Teaching History with Video Games."

${ }^{6}$ David Jagneaux has written a detailed article on the types of players that can be found in MMORPGs. See David Jagneaux, "The List: The 5 Worst Types of MMO Players," (August 2014), http://www.morpg.com/showFeature.cfm/feature/8849page/1.

${ }^{7}$ For more detailed demographics on the gaming community of MMORPGs see, Nick Yee, "Unmasking the Avatar: The Demographics of MMO Player Motivations, In-Game Preferences, and Attrition," Gamasutra (September 2004), http://www.gamasutra.com/view/feature/130552/unmasking_the_avatar_ the_php?print=1. 
and 'consumes' its history." ${ }^{8}$ The notion of using video games in the classroom is relatively new, but the theories calling for the use of games borrows heavily from many other methodologies and combines several pedagogical techniques. Ultimately, the use of MMORPGs helps teachers merge classroom instruction with an active hands-on approach normally not a part of the teaching of history. Students do not passively learn about the history, they live it in a virtual setting. Thus, it gets the students actively involved in the learning process and makes the process of history more relevant to them. Finally, the use of MMORPGs and other computer games can teach students to think critically about the way our society uses history and even begin to understand how the commodification of history through various multimedia vehicles can alter our understanding of past events.

While I originally developed the MMORPG assignment for use in my upper-level class "Pirates in the Americas," its initial pedagogical success in engendering student interest has led me to adopt this teaching technique for a future course on the Atlantic World. The best approach in choosing a MMORPG or video game for classroom use is to select it in the same manner as one picks a book to assign for the class-find several games, play them for a period of time, and then decide which one best suits the subject matter for the class. Most MMORPGs are free to play and thus easy to implement in classes.

There are an endless number of MMORPGs at the moment, but only a small group focus on historical subjects. Game maker Creative Assembly has a series of team-based MMORPGs from their Total War title series that let players control armies of warriors led by iconic commanders from history. A key aspect to these battles is the focus on historical accuracy in unit structure, weapons, armor, and military specialization of units. Wargaming.net offers a flight combat MMO simulation called World of Warplanes that takes place in the period from World War I to just after World War II, allowing players to fly historically accurate replicas of planes in their contemporary period and to test their piloting skills against real opponents. Another combat flight simulator called War Thunder is available from developer Gaijin Entertainment. The game currently focuses on combat aircraft from World War II and provides the player with a realistic flight combat experience. There are also several MMORPGs featuring tank combat during World War II, warship combat in the Pacific theater, and the amphibious landing in Normandy. Stronghold Kingdoms is a medieval-themed game developed by Firefly Studios that allows players to build a village into a mighty city by researching new technologies, expanding trade connections, and defending their lands from raiders by building castles. And finally, Diplomacy Online is a multiplayer webbased implementation of the turn-based strategy game by Avalon Hill. In this game, players try to conquer Europe by using strategy and diplomacy to make deals and

\footnotetext{
${ }^{8}$ Andrew McMichael, "PC Games and the Teaching of History," The History Teacher 40 (February 2007): 203.
} 
alliances with other players as well as sabotage opponents' plans when necessary to achieve individual goals.

Although a majority of MMORPGs feature combat scenarios and war themes, there are games that explore other topics. The Great Merchant Online developed by JoyOn emphasizes commercial trading and becoming a great merchant. In the game, players travel across Eurasia and earn fortunes by finding advantageous deals, establishing new trade routes, making new contacts, investing in villages, and collecting taxes within their trading realms. Salem, developed by Sea Tribe and set in a fantastical New England, allows players to take on the role of colonists seeking to make lives for themselves in the New World. It features a crafting, farming, and building system based on seventeenth-century alchemy, but also allows players to encounter people and creatures based on actual colonist folklore, which includes but is not limited to Squonks, Hidebehinds, and witches. In the course of the game, players will scavenge for food, harvest natural resources, craft tools and homes, participate in a barter based economy, find themselves in competition with rival settlements, and even deal with vigilantes and mob justice.

With so many MMORPG options, there is ample opportunity to use them as classroom resources. It is important to remember that this pedagogical method is as much about making history enjoyable for the student as it is about getting them to dynamically engage in the process of learning. If one designs an assignment properly, students will actively create a historically based experience with their peers through gameplay and successfully engage in research about the historical period. Once gameplay is complete, students should be required to employ historical research and analyze their participation in papers about their experiences. Thus, by combining active and interactive learning experiences, the MMORPG assignment enhances comprehension of how historical events are created and interpreted while expanding on knowledge delivered through traditional means. As a result, the use of MMORPGs in the classroom gives students a richer understanding of history, the historical process, and the historian's craft. 